$\xi=-1$

\title{
Semi-automated approach in the evaluation of low bone mass using clavicle radiogrammetry technique
}

\author{
U. Snekhalatha $^{1}$, D. Ashok Kumar ${ }^{1}$, Padmajavasan ${ }^{1}$ \\ ${ }^{1}$ Department of Bio medical Engineering, SRM Institute science and Technology, Chennai, Tamil Nadu, India \\ *Corresponding author E-mail: sneha_samuma@yahoo.co.in
}

\begin{abstract}
Background: Low bone mineral density increasing with age is a universally observed phenomenon. This leads to osteoporosis, which is a regressive change that occurs in the bone and it is diagnosed before the occurrence of fractures. The dual energy $\mathrm{x}$-ray absorptiometry (DXA) is considered to be the standard measurement for the detection of bone mineral density (BMD).

Objectives: To measure the various bone mass indices in the clavicle bone by radiogrammetric method from a posterior-to-anterior (PA) view of chest digital X-ray using semi- automated method.

Methods: Forty women whose mean age was found to be $46.05 \pm 15.53$ years were included in this study. For the total population ( $\mathrm{n}=40$ ), the right femur BMD was acquired by DXA scanner. The digital chest radiographs were taken for all the subjects. In all cases, the geometrical variables such as periosteal width (CLR-D), endosteal width (CLR-d), cortical thickness (CLR-CT) and percentage cortical thickness \%(CLR-CT) were measured in the right clavicle bone region by semi-automated method approach developed in MATLAB software. Results: The $\mathrm{CL}_{\mathrm{R}}-\mathrm{CT}(\mathrm{r}=0.77)$ as well as with \% $\mathrm{CL}_{\mathrm{R}}-\mathrm{CT}(\mathrm{r}=0.72)$ has provided statistically significant correlation $(\mathrm{p}<0.01)$ with the total hip BMD in the total population studied. The pre-menopausal and post-menopausal of the studied population demonstrated a high significance value of $(\mathrm{p}<0.01)$.

Conclusion: The semi-automated measurement of low bone mass indices in clavicle radiogrammetry will be useful in the evaluation of low bone mass in post-menopausal women and elderly aged population. This method can be used as a screening tool for mass population, especially in rural India.
\end{abstract}

Keywords: Bone Mineral Density; Osteoporosis; Clavicle Radiogrammetry; Cortical Thickness.

\section{Introduction}

Osteoporosis is a metabolic disorder which will reduce the bone thickness and bone mineral content which produce a weaker spot that leads to risk of fracture, mainly over the spine, pelvis, hip, wrist or upper arm. This ailment or its related fractures are a vital reason concerning mortality and morbidity. The Asians were most prevalently affected by vertebral fractures similar to Caucasian populations. It was estimated that more than $50 \%$ people will be affected by osteoporosis in Asia by the year 2050.In India, minority of people having health insurance where the hip fractures are not considered in insurance scheme [1].

Long et al [2] a have done a calculation to assess the cortical bone thickness of femur from area bone mineral thickness from clinical dual energy x-ray absorptiometry (DXA). The endocortical diameters and cortical thickness have been assessed by using the estimations regarding cross-range or the vile cortical thicknesses which depend on the structure model of hip [3]. Different enhancement has been suggested in conformity with the preliminary radiogrammetric method, includes the averaging other sites in the same bone [4]. The computerized technique primarily based about radiogrammetric than textural evaluation of the ternary middle metacarpal bones showed excessive precision [5].

The various semi-quantitative methods which is ranged from easy traditional radiography in conformity with sophisticated photon absorptiometry [6,7]. DXA is considered as a standard measurement technique for bone mineral density (BMD) which is availa- ble only in multi specialty and super-specialty hospitals. This technique is not affordable by the rural population due to high cost. The measurement related to cortical width of tubular bone which reflects with age in the bone formation and resorption.

\section{Literature work}

Several authors have performed the segmentation methods such active shape models, canny edge detection algorithm to segment the regions of hand bones, trabecular bone, femoral neck, femur region using digital $\mathrm{x}$-ray radiogrammetry (DXR) for the evaluation of the osteoporosis [8-10]. Rosholm et al established automated method for estimation of BMD from hand radiograph and fore arm. They found that the BMD DXR was closely correlated with the BMD at distal forearm, total hip, spine and femoral neck. Finally they suggested that the DXR BMD provided good correlation with distal forearm BMD [11]. Bouxsein et al determined that the DXR-BMD measurement predicts the fracture risk in various regions such as wrist, hip and vertebral. They compared the DXR$\mathrm{BMD}$, proximal and distal BMD, lumbar spine and femoral BMD of vertebral fracture with healthy controls and predicted the fracture risk in various regions of the body [12]. Bach-Mortensen et al in their follow-up study found that DXR-BMD negatively correlated with the age, fracture and smoking. They obtained the statistically significant correlation between the DXR-BMD and the wrist fractures, humeral fractures and vertebral fractures. They concluded that the estimated BMD from DXR at metacarpal re- 
gions predicted the later risk of osteoporotic fractures [13]. Kalvesten et al compared the performance of DXR with FRAX with DXA in differentiating the osteoporotic fracture with the various regions such as hip, spine, forearm, shoulder and femoral neck. They observed that the DXR-BMD predicted the femoral neck osteoporosis at higher rate compared to FRAX [10].

To the best of the knowledge, this study is the first study to segment the clavicle bone region by semi-automated method for estimation of low bone mass. Clavicle radiogrammetry by digital chest X-ray will be useful in evaluation of osteoporosis [14].The main aim and objective of this study was to measure the various bone mass indices in the right clavicle bone by radiogrammetric method from a standard digital chest X-ray using semi-automated method.

\section{Materials and methods}

\subsection{Subjects}

A medical camp was conducted for osteoporosis during the month of august and December 2010 at Sri Ramaswamy Memorial (SRM) Hospital and Medical Research Centre, SRM University, Chennai, India. The exclusion criteria were participants with known bone cancer, renal impairment and kidney diseases. Forty Indian women (pre menopausal and post menopausal) with a mean age of $46.05 \pm 15.53$ years were included. None of the subjects had previous fractures due to osteoporosis.

\subsection{Methods}

Clavicle bone mass indices measurements

A standard digital $\mathrm{X}$-ray was taken in posterior to anterior (PA) view of chest using an digital X-ray machine with standard tube voltage of and tube current conditions in all the subjects.

The clavicle bone mass indices were calculated in a semiautomated way by developing an algorithm using MATLAB R2013a software. In this method, clavicle bone mass indices were estimated by using multi-threshold based segmentation algorithm. The algorithm for semi-automated clavicle bone segmentation was given as follows:

1) The chest $\mathrm{x}$-ray image using digital $\mathrm{x}$-ray radiogrammetry is taken as input image.

2) The lung region was segmented using level set algorithm for identifying region of interest (ROI) of clavicle bone area

3) The binary mask is applied over the lung area using pixel based histogram thresholding.

4) The binary masks were generated from input gray-level image using an iterative thresholding algorithm.

5) From that binary formation, the segmented lung region was labeled and considered as ROI for our process.

6) The optimal thresholding technique was implemented to extract a region of bone area which is high intensity and low intensity area of lung region is neglected..

7) The right and left clavicle were segmented semiautoamtically by selecting the ROI and the periosteal and endosteal width were calculated by using the pixel difference between bone pixel intensity.

8) The obtained output value of periosteal and endosteal width are in terms of number of pixels, hence the pixel value was converted to millimeter by multiplying by value of 0.2646

9) The bone mass indices such as periosteal width of right clavicle $\left(\mathrm{CL}_{R}-\mathrm{D}\right)$; (b) the endosteal width of right clavicle $\left(\mathrm{CL}_{\mathrm{R}}-\mathrm{d}\right)$ were measured, from which cortical thickness of right clavicle is computed. Fig. 1 shows the sample chest $\mathrm{X}$ ray measurement in clavicle bone.

The bone mass indices were calculated as given below:

1) Cortical thickness of right Clavicle $\left(\mathrm{CL}_{R}-\mathrm{CT}\right)=(\mathrm{D}-\mathrm{d})$;

2) Percentage of cortical thickness of right Clavicle \% $\left(\mathrm{CL}_{R^{-}}\right.$ $\mathrm{CT})=(\mathrm{D}-\mathrm{d} / \mathrm{D}) * 100$.

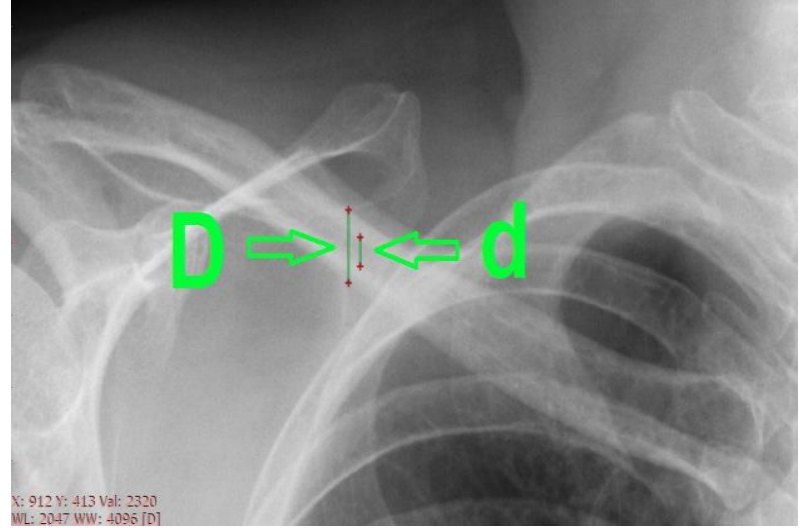

Fig. 1: Sample Chest X-Ray Measurement in Clavicle Bone.

The total hip BMD (T-BMD) was measured by the DXA Scanner. The classification by T-score was done using a measured mean \pm SD $(1.06 \pm 0.15)$ for T- BMD in young normal south Indian women aged 25-35 years. The study subjects were subdivided based on calculated $\mathrm{T}$ score and the values were measured according to world health organization (WHO) diagnostic criteria as follows: (1) normal - $(\mathrm{n}=19$, mean $\pm \mathrm{SD}$ age $=37.38 \pm 9.82$ years $)$ (those with $\mathrm{T}$ score $\geq-1)$; (2) low bone mass $(\mathrm{n}=21$, mean \pm SD age $55.63 \pm 15.19$ years) combining osteopenia and osteoporosis (those with $\mathrm{T}$ score above -1 );

\subsection{Statistics}

Statistical analysis was done using SPSS software package version 17.0 (SPSS Inc., Chicago, IL, USA). The relationship between cortical measurements and DXA were obtained by Pearson correlation. The difference between the studied groups was analyzed using student's t-test.

\section{Results}

\subsection{Statistical correlation}

Table 1 depicts the Statistical correlation of radiogrammetry measurements and DXA in total population. The T-BMD measured by DXA negatively correlated with age $(r=-0.71, p<0.01)$ and the cortical measurement parameters of CLR-CT $(\mathrm{r}=0.77)$ and $\% \mathrm{CL}_{\mathrm{R}}-\mathrm{CT}(\mathrm{r}=0.72)$ are correlated significantly at level of $(\mathrm{p}$ $<0.01$ ). Table 2 illustrates the Statistical correlation of radiogrammetry measurements with DXA in post-menopausal women. The T-BMD measured by DXA negatively correlated with age ( $\mathrm{r}$ $=-0.56, \mathrm{p}<0.01)$ and the measured parameters CLR-CT $(\mathrm{r}=$ $0.73)$ and $\% \mathrm{CL}_{\mathrm{R}}-\mathrm{CT}(\mathrm{r}=0.78)$. Fig. 2 and 3 showed Correlation between $\mathrm{CLR}_{\mathrm{R}}-\mathrm{CT}(\mathrm{mm})$ and \% CLR-CT with T-BMD $\left(\mathrm{g} / \mathrm{cm}^{2}\right)$ in total women studied. 
Table 1: Statistical Correlation of Measured Radiogrammetry Variables with DXA in Total Studied Population

\begin{tabular}{|c|c|c|c|c|c|c|}
\hline \multirow[b]{2}{*}{ Description } & \multicolumn{6}{|c|}{ DXA -Right proximal femur $(n=40)$} \\
\hline & Parameters & $\begin{array}{l}\text { Neck-BMD } \\
\left(\mathrm{g} / \mathrm{cm}^{2}\right)\end{array}$ & $\begin{array}{l}\text { Ward-BMD } \\
\left(\mathrm{g} / \mathrm{cm}^{2}\right)\end{array}$ & $\begin{array}{l}\text { Trabecular-BMD } \\
\left(\mathrm{g} / \mathrm{cm}^{2}\right)\end{array}$ & $\begin{array}{l}\text { Shaft-BMD } \\
\left(\mathrm{g} / \mathrm{cm}^{2}\right)\end{array}$ & $\begin{array}{l}\text { Total hip-BMD } \\
\left(\mathrm{g} / \mathrm{cm}^{2}\right)\end{array}$ \\
\hline \multirow{5}{*}{ Baseline variables } & Age(years) & $-.715^{* *}$ & $-.640^{* *}$ & $-.677^{* *}$ & $-.695^{* *}$ & $-.718^{* *}$ \\
\hline & Height $(\mathrm{cm})$ & $.337^{*}$ & .280 & .260 & .304 & $.313^{*}$ \\
\hline & Weight(kg) & $.385^{*}$ & $.416^{* *}$ & $.456^{* *}$ & $.519^{* *}$ & $.510^{* *}$ \\
\hline & $\operatorname{BMI}\left(\mathrm{kg} / \mathrm{m}^{2}\right)$ & .257 & $.317^{*}$ & $377^{*}$ & $.425^{* *}$ & $.408^{* *}$ \\
\hline & $\mathrm{CL}_{\mathrm{R}}-\mathrm{D}(\mathrm{mm})$ & .007 & .001 & -.030 & -.051 & -.044 \\
\hline \multirow{2}{*}{$\begin{array}{l}\text { Chest digital x-ray (right clavi- } \\
\left.\text { cle }\left(C_{R}\right)\right)\end{array}$} & $\mathrm{CL}_{\mathrm{R}}-\mathrm{d}(\mathrm{mm})$ & $-.508^{* *}$ & $-.509^{* *}$ & $-.541^{* *}$ & $-.560^{* *}$ & $-.572^{* *}$ \\
\hline & $\begin{array}{l}\mathrm{CL}_{\mathrm{R}^{-}} \\
\mathrm{CT}(\mathrm{mm})\end{array}$ & $.735^{* *}$ & $.729^{* *}$ & $.743^{* *}$ & $.747^{* *}$ & $.771^{* *}$ \\
\hline Semi-automated method & $\begin{array}{l}\mathrm{CL}_{\mathrm{R}^{-}} \mathrm{CT} \\
(\%)\end{array}$ & $.671^{* *}$ & $.670^{* *}$ & $.692^{* *}$ & $.702^{* *}$ & $.723^{* *}$ \\
\hline
\end{tabular}

$* \mathrm{p}<0.05, * * \mathrm{p}<0.01$

Table 2: Statistical Correlation of Measured Radiogrammetry Variables with DXA in Post-Menopausal Population

\begin{tabular}{|c|c|c|c|c|c|c|}
\hline \multirow[b]{2}{*}{ Description } & \multicolumn{6}{|c|}{ DXA (Right proximal femur $\mathrm{N}=20$ ) } \\
\hline & Parameters & $\begin{array}{l}\text { Neck-BMD } \\
\left(\mathrm{g} / \mathrm{cm}^{2}\right)\end{array}$ & $\begin{array}{l}\text { Ward-BMD } \\
\left(\mathrm{g} / \mathrm{cm}^{2}\right)\end{array}$ & $\begin{array}{l}\text { Trabecular-BMD } \\
\left(\mathrm{g} / \mathrm{cm}^{2}\right)\end{array}$ & $\begin{array}{l}\text { Shaft-BMD } \\
\left(\mathrm{g} / \mathrm{cm}^{2}\right)\end{array}$ & $\begin{array}{l}\text { Total hip-BMD } \\
\left(\mathrm{g} / \mathrm{cm}^{2}\right)\end{array}$ \\
\hline \multirow{4}{*}{ Base line variables } & Age(years) & $-.585^{* *}$ & $-.463^{*}$ & $-.499^{*}$ & $-.529^{*}$ & $-.562^{* *}$ \\
\hline & Weight(kg) & $.666^{* *}$ & $.621^{* *}$ & $.636^{* *}$ & $.718^{* *}$ & $.713^{* *}$ \\
\hline & $\mathrm{BMI}\left(\mathrm{kg} / \mathrm{m}^{2}\right)$ & $.624^{* *}$ & $.599^{* *}$ & $.668^{* *}$ & $.734^{* *}$ & $.715^{* *}$ \\
\hline & $\mathrm{CL}_{\mathrm{R}}-\mathrm{D}(\mathrm{mm})$ & -.261 & -.278 & -.310 & -.367 & -.368 \\
\hline \multirow{2}{*}{$\begin{array}{l}\text { Chest digital x-ray (right clavi- } \\
\left.\text { cle }\left(C_{R}\right)\right)\end{array}$} & $\mathrm{CL}_{\mathrm{R}}-\mathrm{d}(\mathrm{mm})$ & $-.630^{* *}$ & $-.653^{* *}$ & $-.653^{* *}$ & $-.681^{* *}$ & $-.701^{* *}$ \\
\hline & $\begin{array}{l}\mathrm{CL}_{\mathrm{R}^{-}} \\
\mathrm{CT}(\mathrm{mm})\end{array}$ & $.750^{* *}$ & $.768^{* *}$ & $.729^{* *}$ & $.705^{* *}$ & $.737^{* *}$ \\
\hline Semi-automated method & $\begin{array}{l}\mathrm{CL}_{\mathrm{R}^{-}} \mathrm{CT} \\
(\%)\end{array}$ & $.748^{* *}$ & $.775^{* *}$ & $.751^{* *}$ & $.752^{* *}$ & $.781^{* *}$ \\
\hline
\end{tabular}

$* \mathrm{p}<0.05, * * \mathrm{p}<0.01$

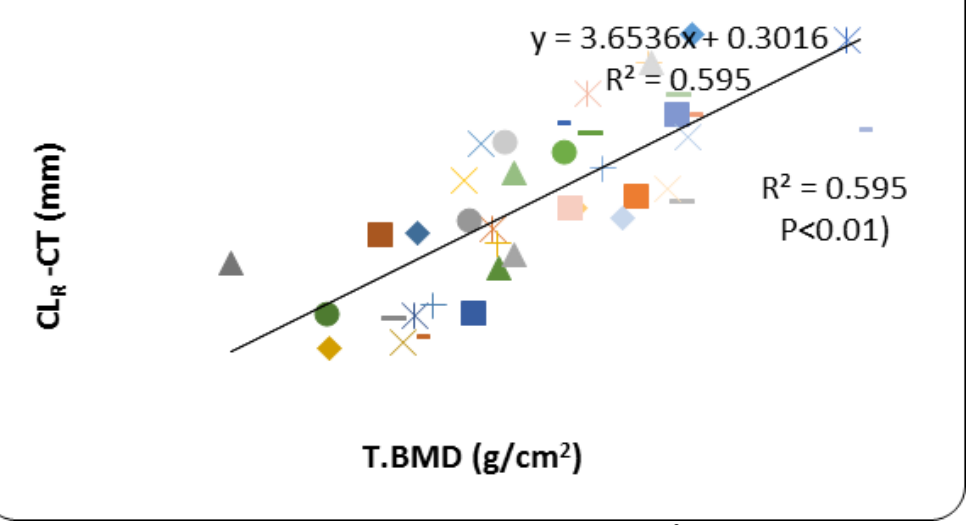

Fig. 2: Correlation between $\mathrm{CL}_{\mathrm{R}-} \mathrm{CT}(\mathrm{Mm})$ and T-BMD $\left(\mathrm{G} / \mathrm{Cm}^{2}\right)$ in Total Women Studied

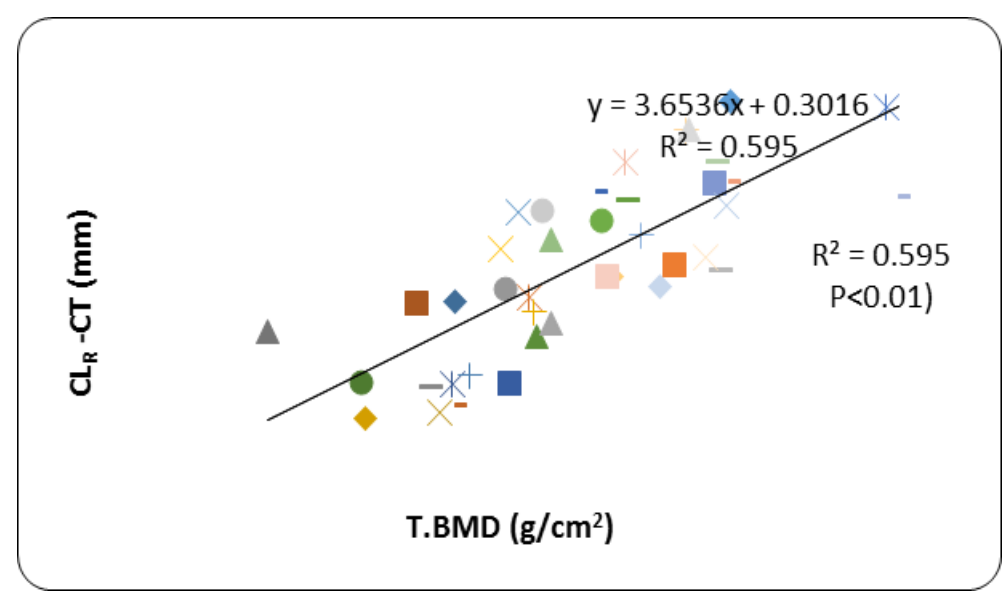

Fig. 3: Correlation between $\mathrm{CL}_{\mathrm{R}}-\mathrm{CT}(\%)$ and T-BMD $\left(\mathrm{G} / \mathrm{Cm}^{2}\right)$ in Total Women Studied. 
Table 3: Statistical Differences between Pre-Menopausal and Post-Menopausal Women

\begin{tabular}{|c|c|c|c|c|}
\hline Method & Variables & Pre-menopausal $(n=20)$ & Postmenopausal $(\mathrm{n}=20)$ & Statistical significance \\
\hline \multirow{3}{*}{ Demographic features } & Age(years) & $32.60 \pm 4.17$ & $59.50 \pm 9.83$ & 0.00 \\
\hline & Height(cm) & $152.30 \pm 7.16$ & $148.70 \pm 6.02$ & 0.09 \\
\hline & Weight(kg) & $55.70 \pm 8.94$ & $53.45 \pm 10.52$ & 0.47 \\
\hline \multirow{5}{*}{ DXA(Right proximal femur) } & Neck-BMD $\left(\mathrm{g} / \mathrm{cm}^{2}\right)$ & $1 \pm 0.18$ & $0.72 \pm 0.14$ & 0.00 \\
\hline & Ward-BMD $\left(\mathrm{g} / \mathrm{cm}^{2}\right)$ & $0.81 \pm 0.23$ & $0.53 \pm 0.16$ & 0.00 \\
\hline & Trabecular-BMD $\left(\mathrm{g} / \mathrm{cm}^{2}\right)$ & $0.78 \pm 0.15$ & $0.56 \pm 0.15$ & 0.00 \\
\hline & Shaft-BMD $\left(\mathrm{g} / \mathrm{cm}^{2}\right)$ & $1.20 \pm 0.20$ & $0.87 \pm 0.23$ & 0.00 \\
\hline & Total hip-BMD $\left(\mathrm{g} / \mathrm{cm}^{2}\right)$ & $1.01 \pm 0.17$ & $0.72 \pm 0.18$ & 0.00 \\
\hline \multirow{4}{*}{ Chest digital x-ray (right clavicle $\left(\mathrm{CL}_{\mathrm{R}}\right)$ ) } & $\mathrm{CL}_{\mathrm{R}}-\mathrm{D}(\mathrm{mm})$ & $8.79 \pm 1.28$ & $8.92 \pm 1.28$ & 0.71 \\
\hline & $\mathrm{CL}_{\mathrm{R}}-\mathrm{d}(\mathrm{mm})$ & $4.72 \pm 1.77$ & $6.05 \pm 1.77$ & 0.00 \\
\hline & $\mathrm{CL}_{\mathrm{R}^{-}} \mathrm{CT}(\mathrm{mm})$ & $4.07 \pm 1.04$ & $2.87 \pm 1.04$ & 0.00 \\
\hline & $\mathrm{CL}_{\mathrm{R}^{-}} \mathrm{CT}(\%)$ & $46.41 \pm 12.97$ & $32.96 \pm 12.97$ & 0.00 \\
\hline
\end{tabular}

Table 4: Statistical Differences between Control Subjects and Low Bone Mass Women

\begin{tabular}{|c|c|c|c|c|}
\hline Method & Variables & Control $(n=21)$ & Low bone mass $(\mathrm{n}=19)$ & Statistical significance \\
\hline \multirow{3}{*}{ Demographic features } & Age(years) & $37.38 \pm 9.82$ & $55.63 \pm 15.19$ & 0.00 \\
\hline & Height $(\mathrm{cm})$ & $152.76 \pm 6.37$ & $148 \pm 6.47$ & 0.02 \\
\hline & Weight $(\mathrm{kg})$ & $58.52 \pm 9.12$ & $50.21 \pm 8.55$ & 0.01 \\
\hline \multirow{5}{*}{ DXA(Right proximal femur) } & Neck-BMD $\left(\mathrm{g} / \mathrm{cm}^{2}\right)$ & $1.01 \pm 0.17$ & $0.70 \pm 0.10$ & 0.00 \\
\hline & Ward-BMD $\left(\mathrm{g} / \mathrm{cm}^{2}\right)$ & $0.84 \pm 0.21$ & $0.49 \pm 0.10$ & 0.00 \\
\hline & Trabecular-BMD $\left(\mathrm{g} / \mathrm{cm}^{2}\right)$ & $0.80 \pm 0.13$ & $0.52 \pm 0.11$ & 0.00 \\
\hline & Shaft-BMD $\left(\mathrm{g} / \mathrm{cm}^{2}\right)$ & $1.24 \pm 0.16$ & $0.81 \pm 0.16$ & 0.00 \\
\hline & Total hip-BMD $\left(\mathrm{g} / \mathrm{cm}^{2}\right)$ & $1.04 \pm 0.14$ & $0.68 \pm 0.12$ & 0.00 \\
\hline \multirow{4}{*}{ Chest digital x-ray (right clavicle $\left(\mathrm{CL}_{\mathrm{R}}\right)$ ) } & $\mathrm{CL}_{\mathrm{R}}-\mathrm{D}(\mathrm{mm})$ & $8.80 \pm 0.99$ & $8.91 \pm 1.31$ & 0.78 \\
\hline & $\mathrm{CL}_{\mathrm{R}}-\mathrm{d}(\mathrm{mm})$ & $4.60 \pm 0.88$ & $6.25 \pm 1.64$ & 0.00 \\
\hline & $\mathrm{CL}_{\mathrm{R}^{-}} \mathrm{CT}(\mathrm{mm})$ & $4.21 \pm 0.70$ & $2.65 \pm 0.78$ & 0.00 \\
\hline & $\mathrm{CL}_{\mathrm{R}^{-}} \mathrm{CT}(\%)$ & $47.92 \pm 6.87$ & $30.59 \pm 10.47$ & 0.00 \\
\hline
\end{tabular}

\subsection{Statistical difference between the groups}

Table 3 and 4 shows the statistical differences between premenopausal and post-menopausal women and in normal and low bone mass population. In this study, it was found that $47.5 \%$ of the women studied were found to have low bone mass. The measured mean T-BMD values in normal women was $1.04 \mathrm{~g} / \mathrm{cm}^{2}$, whereas, in low bone mass women, it was $0.68 \mathrm{~g} / \mathrm{cm}^{2}$ and its percentage decrease was found to be $34.61 \%$. In low bone mass women, the percentage decrease in height and weight was decreased by $3.1 \%$ and $14.2 \%$ respectively, when compared with normal women.

\subsection{Radiogrammetric measurements on the Digital chest X-ray PA view radiograph using semi-automated method}

The mean values of periosteal width and endosteal width were found to be increased in the low bone mass women than in the normal women. It was observed that the mean values of $\mathrm{CL}_{\mathrm{R}}-\mathrm{CT}$ and \% CLR-CT were found to be decreased by $37.05 \%$ and $36.1 \%$ respectively in the low bone mass women than in the normal women. The measured radiogrammetry variables from the semiautomated approach at the clavicle region was statistically significant at the level of ( $p<0.01)$ with CLR-CT and \% CLR-CT in both groups. The algorithm was implemented for measuring the clavicle bone mass indices of the x-ray images. Fig. 4 showed the detailed output of the measurement of cortical bone measurements in right clavicle region. 


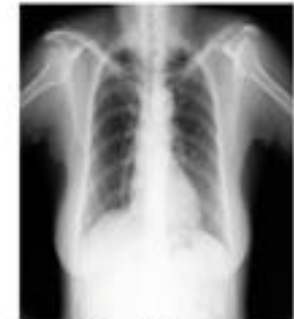

Input Image

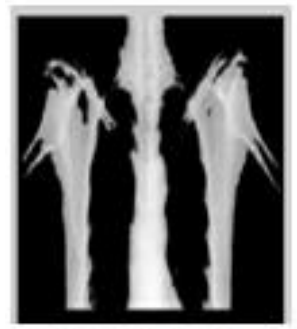

Removal of lungregion

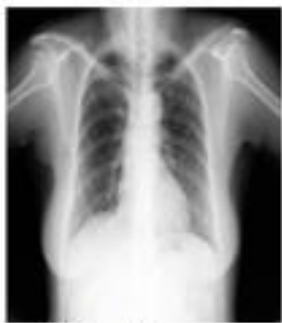

Filtered Image

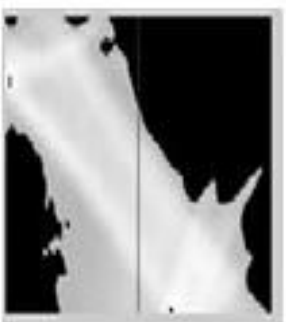

Right clavicle seprentation

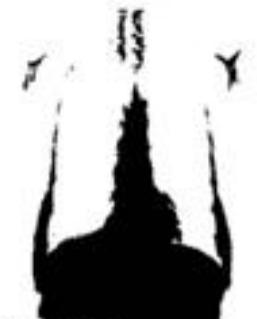

Binarized lung area Image

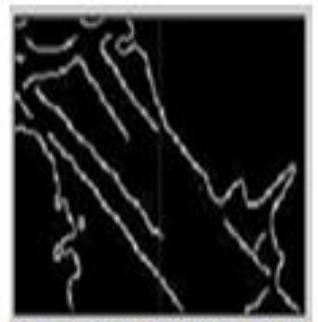

BONE AREA RESULT (mm)
Over-all Bone

12.6667

Inner Clavicle

s. 3333

\section{RIGHT CLAVICLE}

Fig. 4: The Detailed Output of the Measurement of Cortical Bone Measurements in Right Clavicle Region.

\section{Discussion}

In the total population, the variables measured by radiogrammetry method such as $\mathrm{CL}_{\mathrm{R}}-\mathrm{CT}$ and \% $\mathrm{CL}_{\mathrm{R}}-\mathrm{CT}$ showed a significant correlation $(\mathrm{p}<0.01)$ with T-BMD which are in agreement with Kumar et al findings [15]. In our study, it was predicted that the TBMD values have a strong correlation with cortical thickness and percentage cortical thickness of clavicle respectively. The results from this study coincides with two earlier studies which showed that BMI and weight loss are the variables which are the two independent factors considered for risk of fracture due to osteoporosis and for hip bone loss in both genders [16-19]. It was also found that $47.5 \%(19 / 40)$ and $80 \%(16 / 20)$ of the total studied population and post-menopausal group were predicted as low BMD. The previous study shows that about $58.6 \%$ of the post-menopausal women were predicted to be osteoporosis [6].

The semi-automated approach using radiogrammetry techniques has been tested in the various region of interest especially in metacarpal and femoral shaft region which shows a high degree of correlation with T-BMD [15]. Roberts et al performed semiautomated segmentation to detect the vertebral fracture in DXA vertebral fracture assessment (VFA) images using statistical appearance model in evaluation of osteoporosis [20]. Puri et al implemented the semi-automated method in segmenting the bone regions of femoral shaft, total hip and a femoral neck region [21]. Santhoshini et al computed the segmentation techniques such as canny edge detection algorithm and thresholding to segment the femur bone regions semi- automatically [22]. Hence various authors have performed the segmentation techniques in different regions of interest such as vertebrae, femoral shaft, hip, femoral neck to evaluate the osteoporosis. To the best of our knowledge, this is the first study to perform the correlations between T-BMD by DXA, CLR-CT and \% $\mathrm{CL}_{R}-\mathrm{CT}$ of the clavicle in a semiautomated manner. One of the main limitations of the study was locating the region of interest in the clavicle bone. The bone segmentation is to be done carefully in both the clavicle, where there is possibility of overlapping of other bone regions in the segmentation process.

\section{Conclusion}

The semi-automated measurement of low bone mass indices in clavicle radiogrammetry of chest $\mathrm{x}$-ray was found to be useful in evaluation of low bone mass in post-menopausal women and elderly aged population. This method can be used as screening tool, especially in rural population of India.

\section{Acknowledgements}

The authors would like to provide their sincere thanks to SRM hospital and research center for providing the infrastructure facilities to acquire the data from the patients.

\section{References}

[1] A.Mittal, E.Lau, "The Asian Audit: Epidemiology, Costs and Burden of Osteoporosis in Asia", International Osteoporosis Foundation, pp 1-58, 2009.

[2] Y.Long W.D.Leslie and Y.Luo, "Study of DXA-derived lateralmedial cortical bone thickness in assessing hip fracture risk". Bone Rep. Vol 2. pp.44-51, 2015

[3] T.J.Beck, A.C.Looker, C.B.Ruff, H.Sievanen and H.W.Wahner, "Structural trends in the aging femoral neck and proximal shaft:Analysis of the third national health and nutrition examination survey dual-energy x-ray absorptiometry data”. J.Bone Miner.Res. Vol 15. $1297-2304, \quad 2000$ https://doi.org/10.1359/jbmr.2000.15.12.2297.

[4] E.Chan, V. Pandith , T.E Towheed, D. Brouillard D, et al. "Comparison of the combined cortical thickness of the second metacarpal with the Sharp's method for scoring hand microradiographs in rheumatoid arthritis". J. Rheumatol. Vol.25. pp.1290-1294, 1998

[5] S.P Nielsen, "The metacarpal index revisited: a brief overview". J. Clin. Densitom, Vol 4. pp.199-207, 2001

[6] M.Anburajan "Evaluation of osteoporosis using conventional radiographic methods and dual energy x-ray absorptiometry." $\mathrm{PhD}$ Thesis, Anna University, Chennai, 1999

[7] M.Anburajan, C.Rethinasabapathi, M.Paul Korath, B.G Ponnappa et al, "Low cost method for diagnosing post-menopausal osteoporosis". In: Singh M, Radhakrishnan S, Patil KM, Reddy MRS (eds) Medical diagnostic techniques and procedures. Narosa Publishers, Chennai, pp. 416-424, 2000

[8] J. Bottcher, A.Pfeil, A.Petrovitch , M.Schmidt, A.Kramer, M.Ludwig, Schafer, M.Gajda, G.Hein, G.Wolf, W.A Kaiser, "Metacarpal index estimated by digital $\mathrm{x}$-ray radiogrammetry as a tool for differentiating rheumatoid arthritis related periarticular osteopenia”. Int J Biomed Sci Vol 2. pp.241-250, 2006

[9] J.R. Elliot, A.J.Fenton, T.Young, A.Mansfied, C.Burton, T.J. Wilkinson, "The precision of digital $\mathrm{x}$-ray radiogrammetry compared with DXA in subjects with normal bone density on osteoporosis". J Clin Densitom Vol 8. pp. 187-190, 2005 https://doi.org/10.1385/JCD:8:2:187.

[10] J. Kalvesten , L.Y Lui , T.Brismar, S.Cummings, "Digital X-ray radiogrammetry in the study of osteoporotic fractures: Comparison to dual energy x-ray absorptiometry and FRAX" Bone Vol 86. pp. 30 35, 2016 https://doi.org/10.1016/j.bone.2016.02.011. 
[11] Rosholm A, Hyldstrup L, Backsgaard L, Grunkin M, Thodberg HH. Estimation of bone mineral density by digital $\mathrm{x}$-ray radiogrammetry: theoretical background and clinical testing.

[12] Bouxsein ML, Palermo L, Yeung C, Black DM. Digital x-ray radiogrammetry predicts hip, wrist and vertebral fracture risk in elderly women: a prospective analysis from the study of osteoporotic fractures. Osteoporosis Int Vol 13. pp.358-365, 2002 https://doi.org/10.1007/s001980200040.

[13] Back-Mortensen P, Hyldstrup L, Appleyard M, Hindso K, Gebuhr $\mathrm{P}$, Sonne-Holm S. Digital X-ray radiogrammetry identifies women at risk of osteoporotic fracture: results from a prospective study. Calcif Tissue Int Vol 79. pp 1-6, 2006 https://doi.org/10.1007/s00223-005-0260-z.

[14] H.C. "Anton Width of clavicular cortex in osteoporosis". Br Med J Vol 1. pp. 409-411, 1969. https://doi.org/10.1136/bmj.1.5641.409.

[15] D.A.Kumar, M.Anburajan, "The role of hip and chest radiographs in osteoporotic evaluation among south Indian women population: a comparative scenario with DXA", J Endocrinol Invest, Vol 37, pp.429-440, 2014. https://doi.org/10.1007/s40618-014-0074-9.

[16] E. Dennison, R. Eastell, C. H.Fall et al," Determinants of bone loss in elderly men and women: a prospective population-based study". $\begin{array}{lllll}\text { Osteoporos Int Vol } 10 . & \text { pp.384-391, } & 1999\end{array}$ https://doi.org/10.1007/s001980050244.

[17] M.T. Hannan, D.T Felson, B.Dawson-Hughes et al, "Risk factors for longitudinal bone loss in elderly men and women: the Framingham osteoporosis study. J Bone Miner Res Vol 15. pp.710-720, 2000 https://doi.org/10.1359/jbmr.2000.15.4.710.

[18] S.R.Cummings, M.C. Nevitt, W.S.Browner et al "Risk factors for hip fracture in white women". New Engl J Med Vol 332. pp. 767773, 1995 https://doi.org/10.1056/NEJM199503233321202.

[19] J.Porthouse, Y.FBirks, D.J. Torgerson, S.Cockayne, S.Puffer, I.Watt, "Risk factors for fracture in a UK population: a prospective cohort study". QJM Vol 97. pp. 569-574, 2004 https://doi.org/10.1093/qjmed/hch097.

[20] M.G.Roberts, E.M.Pacheco, R.Mohankumar, T.F.Cootes, J.E.Adams, "Detection of vertebral fractures in DXA VFA images using statistical models of appearance and a semi-autoamtic segmentation". Osteoporosis Int 2010; Vol 21. pp. 2037-2046, 2010.

[21] G.M. Puri, Blake, K.M. Curran, H.Carr, A.E.B.Moore, N.Colgan, M.J.Connell, P.K.Marsden, "Semi-automatic region of interest validation at the femur in 18F-Fluroide PET/CT". J of Nuclear medicine technology Vol 40. pp. 168-174, 2012 https://doi.org/10.2967/jnmt.111.100107.

[22] P.Santhoshini, R.Tamilselvi, R.Sivakumar , "Automatic segmentation of femur bone features and analysis of osteoporosis," Lecture notes on software Engineering Vol 1. pp. 194-198, 2013.

[23] Meka Bharadwaj, Hari Kishore "Enhanced Launch-Off-Capture Testing Using BIST Designs" Journal of Engineering and Applied Sciences, ISSN No: 1816-949X, Vol No.12, Issue No.3, page: 636643, April 2017.

[24] T. Padmapriya and V. Saminadan, "Priority based fair resource allocation and Admission Control Technique for Multi-user Multiclass downlink Traffic in LTE-Advanced Networks", International Journal of Advanced Research, vol.5, no.1, pp.1633-1641, January 2017. https://doi.org/10.21474/IJAR01/2929.

[25] S.V.Manikanthan and K.srividhya "An Android based secure access control using ARM and cloud computing", Published in: Electronics and Communication Systems (ICECS), 2015 2nd International Conference on 26-27 Feb. 2015, Publisher: IEEE, https://doi.org/10.1109/ECS.2015.7124833. 